\title{
Relationship between Weather Parameters and Female Mosquitoes' Abundance and Distribution in Makurdi, a Mosquito Infested Area in North Central Nigeria
}

\author{
Manyi, M. M.1 ${ }^{1}$; Akaahan, J. T.2; Azua, E.T.3
}

\begin{abstract}
${ }^{1}$ Applied Entomology and Parasitology Unit, Department of Biological Sciences, Federal University of Agriculture, P M B 2373, Makurdi, Benue State, Nigeria

${ }^{2}$ Environmental Science Unit, Department of Biological Sciences, Federal University of Agriculture, P M B 2373, Makurdi, Benue State, Nigeria
\end{abstract}

\begin{abstract}
The relationship between weather parameters and female mosquito populations/distribution were determined in Makurdi from four localities over a 12-month period. Data on temperature, rainfall and relative humidity were obtained using the expertise of the Nigerian Meteorological Agency at the Tactical Air Command headquarters in Makurdi. Adult female mosquitoes (4,320), comprising anophelines and culicines were caught indoors and identified using standard keys and procedures. 1,040 (24.1\%) were Anopheles gambiae sl; 641 (14.8\%) were Aonpheles funestus; 2,418 (56.0\%) were Culex quinquefasciatus while 221(5.1\%) were 'unidentified' Anopheles species. Mean atmospheric temperature was high throughout the study period with peaks in February and March, before the steady rains in April. Mean temperature in the hottest period (February to April) ranged from $35.2^{\circ} \mathrm{C}-38.2^{\circ} \mathrm{C}$. Relative humidity was proportional to rainfall and ranged from $44 \%-86 \%$. Wet seasons had more mosquito vectors than the dry season. Pearsons's correlation showed a significant negative relationship $(\mathrm{P}<0.05)$ between temperature and the abundance and distribution of mosquitoes for all the other species except for Anopheles funestus $(\mathrm{P}>0.05)$. Similarly, there were significant positive correlations $(\mathrm{P}<0.05)$ between both rainfall and relative humidity, and the abundance of the other mosquito species in the study area excluding Anopheles funestus $(\mathrm{P}>0.05)$. Regression showed strong linear relationships $\left(\mathrm{R}^{2}=0.557,0.549\right.$, and 0.637 for temperature, rainfall and humidity respectively) between weather parameters and mosquito population. This work provides baseline data on mosquito vector relationship with weather factors required for vector population control interventions in Makurdi.
\end{abstract}

Keywords: Humidity, Rainfall, Temperature, Female Mosquitoes, Makurdi, Nigeria

\section{Introduction}

The effects of weather factors on both mosquito populations and their distribution as well as on the parasites they transmit have been documented (Shililu et al., 1998; Okogun et al., 2003; Githeko et al., 2000; Service, 2012). According to Laumann (2010), malaria and lymphatic filariasis's epidemiology depends on many factors including the environment (climate, topography and housing). $\mathrm{He}$ further stated that apart from the mosquito vectors themselves, the parasites they transmit have different temperature requirements for reproduction within the mosquito host. For example, Plasmodium vivax cannot reproduce if the temperature is below $15^{\circ} \mathrm{C}, P$. falciparum does not reproduce when the temperature drops below $19^{\circ} \mathrm{C}$.
Ayanda (2009) reported that incidence of malaria is influenced by weather, which affects the ability of the main carrier of malaria parasites and the female anopheline mosquitoes to survive or otherwise. Tropical areas, including Nigeria, have the best combination of adequate rainfall, temperature and humidity allowing for breeding and survival of mosquitoes (Ayanda, 2009). Githeko et al. (2000) reported that optimum temperature of $32{ }^{\circ} \mathrm{C}$ helps in the development and hatching of mosquitoes' eggs and this imply increased transmission of the malaria and lymphatic filarial parasites. Similarly, Service (2012) stated that the higher the temperature, the faster the gonotrophic cycle of mosquitoes and vice versa. 
Shililu et al. (1998) reported that both mosquito population and their Entomological Inoculation Rate (EIR) are reduced by decreasing rainfall amounts. This has also been found to be true by the works of Kasili et al. (2009), who reported that both Culex quinquefasciatus and Anopheles species were found to dominate in the wet season.

Reports from the National Institute of Allergy and Infectious Diseases (NIAID, 2007) pointed out that climate affects both parasites and mosquito vectors and that, mosquitoes cannot survive in low humidity; rainfall expands breeding grounds, and in many tropical areas, malaria and other mosquito vector disease cases increase during the rainy season. Moreover, Service (2012) opined that since mosquitoes must live long enough for the parasites to complete their development within them, environmental factors that affect their survival can influence disease incidence.

However, Okogun et al. (2003) reported that extreme relative humidity retards the activity of mosquitoes, thereby making them stationary in their breeding, biting and resting places. But they also corroborated that high relative humidity and cool shade are environmental factors preferred by mosquitoes for breeding. The National Environmental Education Foundation (NEEF, 2008) also documented some interactions between weather and mosquito populations and reported that 'though, mosquitoes need water for reproduction and warm temperatures to be active, warmer and wetter conditions do not necessarily correspond to more mosquitoes'.

The present study was therefore, aimed at obtaining weather data in order to ascertain if there exist any relationship between them and mosquito proliferation as well as the perceived vector disease transmission in the Makurdi area, with a view to providing a precontrol data that would be useful in any future mosquito control programmes.

\section{MATERIALS AND METHODS \\ Study Area}

This study was carried out between July, 2011 and June, 2012 in Makurdi to cover wet and dry season periods. Makurdi is the capital of Benue State located in the middle belt region, North Central Nigeria (Federal Republic of Nigeria Official Gazette, 2007). It is intersected by the river Benue- a major source of water with other networks of streams, standing pools, over filled and blocked drainages. Tall bushes and fields are easily noticeable in Makurdi, especially during the wet season, even around residential homes and offices. These provide suitable breeding sites for mosquitoes throughout the wet and dry seasons. Data from the Nigerian Metrological Agency Makurdi (NMA, 2011) has shown that the study area is also characteristic of high temperatures, ranging between $30^{\circ} \mathrm{C}-39^{\circ} \mathrm{C}$. This high temperature range is perceived to promote the speedy development and hatching of mosquito eggs. It is thus suspected that temperature may have an impact on transmission of mosquito vector diseases in the selected localities throughout the year. Geographically, Makurdi is located between longitude $8^{\circ} 35^{\prime} \mathrm{E}$ and $8^{\circ} 41^{\prime} \mathrm{E}$ and latitude $7^{\circ} 45^{\prime} \mathrm{N}$ and $9^{\circ} 52^{\prime} \mathrm{N}$ respectively. Makurdi has a climate typical of the middle belt of Nigeria with distinct wet and dry seasons in a year.

Other detailed geographical and regional indices of Makurdi have been provided by the Nigerian Metrological Agency Makurdi (NMA, 2011); Udo (1981) and Nyagba (1995).

\section{Ethical Consideration and Collection of Mosquito Samples}

Verbal informed consent was obtained from the head of each of the randomly selected households before their houses were accessed for mosquito collection in all the study localities. All mosquito samples were collected using standard procedures as provided by the World Health Organisation (WHO, 1975). Sampling units were randomly selected from four localities and due to the present security challenges in Nigeria, the mosquito samples were collected with the help of "fly boys" who were recruited from the various study localities where they were well known by the residents of the localities sampled.

Mosquito samples were collected from 0600-0900 hours at dawn and 1800-2100 hours at dusk from living rooms in the study localities.

These periods of sample collection were chosen because previous studies have shown that most mosquitoes enter houses to feed at early hours of the night and struggle to go out in the early hours of the day to rest outdoors (Service, 2012, Laumann, 2010).

The mosquitoes were collected from dark corners, walls, ceilings, clothing and other objects inside living rooms with the aid of mouth-aspirators, mosquito sweep nets, pyrethrum spray sheets and window trap method where applicable.

The mosquito specimens were kept in holding tubes, inside cooling boxes, and carried to the laboratory on the same day or the following day for characterization, identification, dissection and examination as adopted by (WHO, 1975, Ungureanu, 1972, Goodman et al., 2003, Aigbodion and Nnoka, 2008, Abeyasingha et al., 2009). Those mosquito samples that could not be processed on the same day were refrigerated and worked upon the next day according to the methods of (Ungureanu, 1972).

The mosquito populations for this study were only drawn from indoor-resting mosquitoes, with the 
expectation that they would only be females. However, some male mosquitoes were also caught along with the females and these were therefore, distinguished from the females using key morphological features as described by Service (2012).

\section{Identification of Mosquito Samples}

Dissecting microscope was used for detailed observations and identification of the mosquitoes with particular reference to the head, thorax, wings and hind-legs according to (Gillies and Coetzee, 1987). Morphological characteristics such as length of maxillary palps, wing spots, leg shape, mouthparts and abdominal end model as described by (Oguoma et al., 2010) were used to identify the mosquito species that co-exist in Makurdi. Observations of the morphological features were made at 40x magnification of the microscope.

\section{Collection of Weather Data}

Data on weather parameters (temperature, rainfall and relative humidity) for the twelve month study period, as they affected the population and distribution of mosquito vectors in Makurdi were collected with the help of trained personnel of the Nigerian Meteorological Agency (NMA), Tactical Air Command head quarters in Makurdi, Nigeria.

\section{Statistical analyses of Data}

The Predictive Analytical Software (PASW) Version 18 was used in running Chi-square $\left(\chi^{2}\right)$ statistic, correlation and regression analyses on the data collected.

Significant levels were measured at $95 \%$ confidence level with significant differences considered at $\mathrm{P}<$ 0.05 . Chi-square statistic was considered the best statistic for test of homogeneity across sample localities so as to determine whether or not, the nature of the sample localities affected the distribution of data across them. Correlation analysis was also carried out both at 0.01 and 0.05 levels to determine whether there was any association between the mosquito populations and the weather parameters under consideration, while regression analysis was done to determine the strength of the association where it existed.

\section{RESULTS}

\section{Temperature}

Mean temperature values in the hottest period (February to April) ranged from $35.2^{\circ} \mathrm{C}$ to $38.2^{\circ} \mathrm{C}$. The lowest and highest mean monthly temperature values for the study period were $29.5^{\circ} \mathrm{C}$ and $38.2^{\circ} \mathrm{C}$ respectively (Table $1 \&$ Figure 2). Correlation analysis showed negative association between the mosquito populations and temperature both at 0.01 and 0.05 levels across the study months respectively (Table 2). Regression analysis revealed a strong relationship $\left(\mathrm{R}^{2}=0.557\right)$ between temperature and mosquito population (Figure 5).

\section{Rainfall}

The mean monthly rainfall range during the study period was between $5 \mathrm{~mm}$ and $293.4 \mathrm{~mm}$, distributed over the 12 month study period. The regular rains started in April, 2011 and increased to a peak in October, followed by a total drop in November and then regularized again in April, 2012 to reach another peak in June, 2012. The results showed that there were more rains in the wet season 1 (July-October, 2011) than wet season 2 (April-June, 2012). Rainfall had a visible effect on mosquito vector population in Makurdi; wet seasons had more mosquito vectors than the dry season and vector population was proportional to rainfall (Figure 3). There was a strong positive correlation $(\mathrm{P}<0.05)$ between the mosquito populations and rainfall throughout the study period (Table 2). Regression analysis showed a strong relationship $\left(\mathrm{R}^{2}=0.549\right)$ between rainfall and mosquito population (Figure 6).

\section{Relative Humidity}

Relative humidity ranged from $44 \%$ - $86 \%$, being lowest from December - March and highest from July - October, 2011 and then April - June, 2012. This implies that relative humidity was proportional to rainfall (Fig.4). Relative Humidity was also found to have a positive correlation $(\mathrm{P}<0.05)$ with the mosquito populations during the study period. The strength of this relationship was determined to be strong $\left(R^{2}=0.637\right)$ by regression analysis (Figure 7$)$. The effect of relative humidity on the mosquito population and monthly distribution in Makurdi during the study period is presented in Table 1 and pictorially shown in Figure 4. 
Relationship between Weather Parameters and Female Mosquitoes' Abundance and Distribution in Makurdi, a Mosquito Infested Area in North Central Nigeria

Table1. Monthly Relationship between Weather Data and Mosquito Populations in Makurdi Number and species of mosquitoes collected

Weather Data

\begin{tabular}{|c|c|c|c|c|c|c|c|c|}
\hline $\begin{array}{l}\text { Sample } \\
\text { Months }\end{array}$ & $\begin{array}{l}\text { Anopheles } \\
\text { gambiae }(\%)\end{array}$ & $\begin{array}{l}\text { Anopheles } \\
\text { funestus }(\%)\end{array}$ & $\begin{array}{l}\text { Anopheles } \\
\text { unidentifd( } \\
\%)\end{array}$ & $\begin{array}{c}\text { Culex } \\
\text { quinq }(\%)\end{array}$ & Total (\%) & $\begin{array}{l}\text { Mean } \\
\text { Tempt } \\
\left({ }^{\circ} \mathrm{C}\right)\end{array}$ & $\begin{array}{r}\text { Mean } \\
\text { Rainfall } \\
(\mathrm{mm})\end{array}$ & $\begin{array}{r}\text { Mean } \\
\text { RH }(\%)\end{array}$ \\
\hline July 2011 & $126(25.0)$ & $102(20.0)$ & $10(2.0)$ & $265(52.7)$ & $503(11.6)$ & 30.7 & 87.0 & 84 \\
\hline Aug 2011 & $225(40.3)$ & 109(19.5 & $22(3.9)$ & $202(36.2$ & $558(12.9)$ & 29.5 & 217.4 & 86 \\
\hline Sept 2011 & $141(24.8)$ & $120(21.1)$ & $19(3.3)$ & $289(50.8)$ & $569(13.2)$ & 30.3 & 272.0 & 84 \\
\hline Oct 2011 & $53(16.5)$ & $31(9.7)$ & $8(2.5)$ & $229(71.3)$ & $321(7.4)$ & 30.8 & 293.4 & 84 \\
\hline Nov 2011 & $21(10.4)$ & $10(4.9)$ & $9(4.5)$ & $162(80.2)$ & $202(4.7)$ & 34.0 & 0.00 & 70 \\
\hline Dec 2011 & $10(5.4)$ & $6(3.2)$ & $5(2.7)$ & $165(88.7)$ & $186(4.3)$ & 34.5 & 0.00 & 44 \\
\hline Jan 2012 & $22(12.6)$ & $8(4.6)$ & $14(8.0)$ & $130(74.7)$ & $174(4.0)$ & 34.6 & 0.00 & 47 \\
\hline Feb 2012 & $29(16.3)$ & $14(7.5)$ & $8(2.5)$ & $127(71.3)$ & $178(4.1)$ & 35.9 & 0.50 & 66 \\
\hline March 2012 & $66(22.2)$ & $31(10.4)$ & $24(8.1)$ & $176(59.3)$ & 297(6.9) & 38.2 & 0.00 & 58 \\
\hline April 2012 & $111(35.9)$ & $62(20.1)$ & $33(10.7)$ & $103(33.3)$ & $309(7.1)$ & 35.2 & 143.2 & 71 \\
\hline May 2012 & $120(23.5)$ & $75(14.7)$ & $47(9.2)$ & $268(52.5)$ & $510(11.8)$ & 32.9 & 160.6 & 80 \\
\hline June 2012 & $116(22.6)$ & $73(14.2)$ & $22(4.3)$ & $302(58.9)$ & $513(11.9)$ & 30.6 & 351.9 & 83 \\
\hline Total/Mean & $1,040(24)$ & $641(14.8)$ & $221(5.1)$ & $2,418(56)$ & $4,320(100)$ & 33.1 & 127.13 & 71.42 \\
\hline
\end{tabular}

Table 2: Correlations between Weather Parameters and Mosquito Populations in Makurdi during the 12 Month Study Period

\begin{tabular}{|c|c|c|c|c|c|}
\hline \multirow[b]{3}{*}{$\begin{array}{l}\text { Weather } \\
\text { Parameter }\end{array}$} & \multirow{2}{*}{\multicolumn{2}{|c|}{ Mosquito }} & \multicolumn{2}{|l|}{ species } & \multirow[b]{3}{*}{$\begin{array}{l}\text { Sample } \\
\text { Size(N) }\end{array}$} \\
\hline & & & & & \\
\hline & Culex quinquefasciatus & $\begin{array}{l}\text { Anopheles } \\
\text { gambiae }\end{array}$ & $\begin{array}{l}\text { Anopheles } \\
\text { funestus }\end{array}$ & Anopheles U.I & \\
\hline Temperature & $-0.637 *$ & $-0.701^{*}$ & -0.30 & $-0.721^{* *}$ & 12 \\
\hline Rainfall & $0.617^{*}$ & $0.645^{*}$ & 0.285 & $0.704^{*}$ & 12 \\
\hline Relative Humidity & $0.734 *^{*}$ & $0.775^{* *}$ & 0.284 & $0.678^{*}$ & 12 \\
\hline
\end{tabular}

** Correlation is significant at the 0.01 level (2- tailed), $\mathrm{P}<0.01$

U.I= Unidentified

* Correlation is significant at the 0.05 level (2-tailed), $\mathrm{P}<0.05$ 
Relationship between Weather Parameters and Female Mosquitoes' Abundance and Distribution in Makurdi, a Mosquito Infested Area in North Central Nigeria

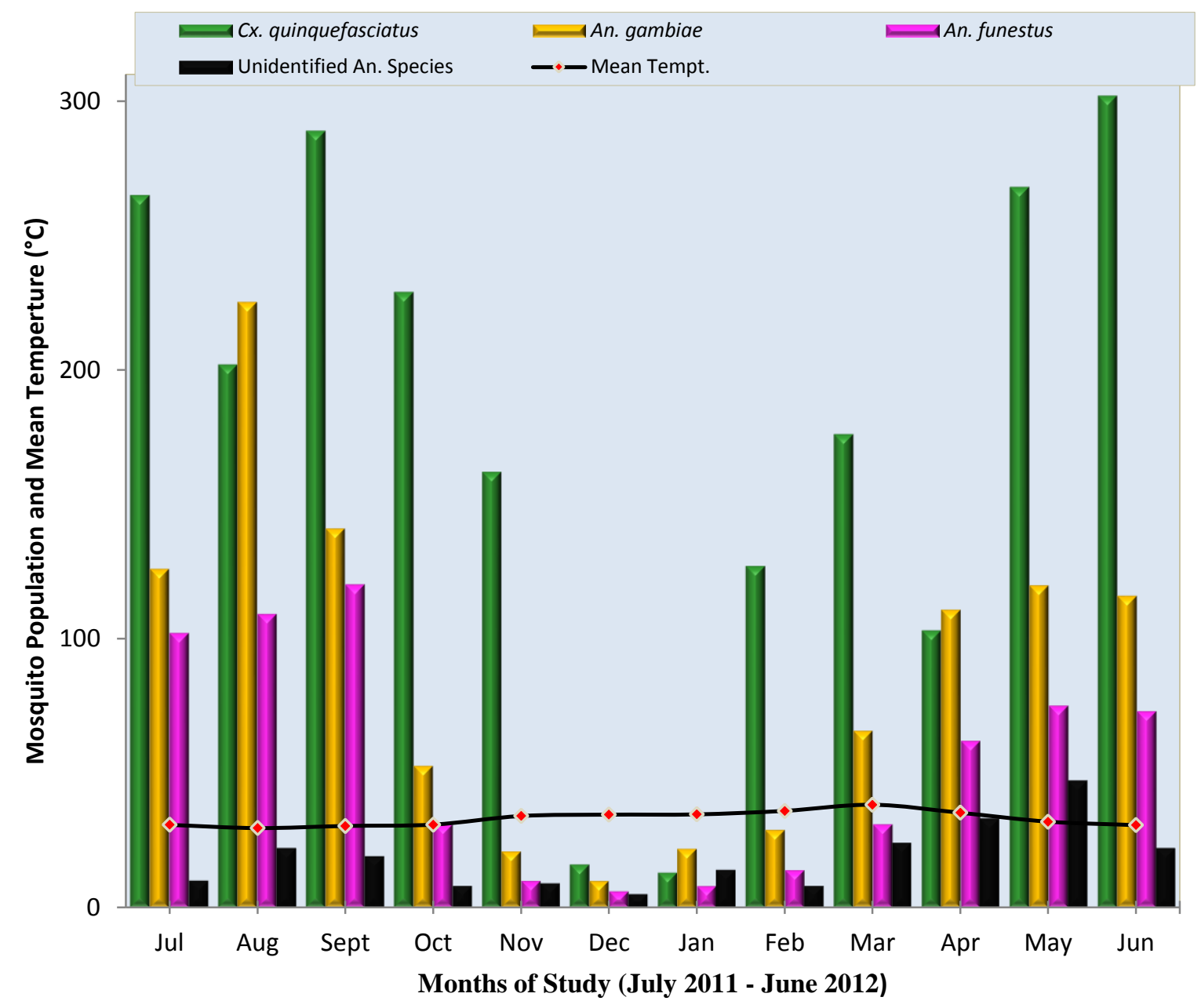

Fig. 2 Distribution of Mosquito Species in Relation to Monthly Mean Values of Temperature in Makurdi, Nigeria. 
Relationship between Weather Parameters and Female Mosquitoes' Abundance and Distribution in Makurdi, a Mosquito Infested Area in North Central Nigeria

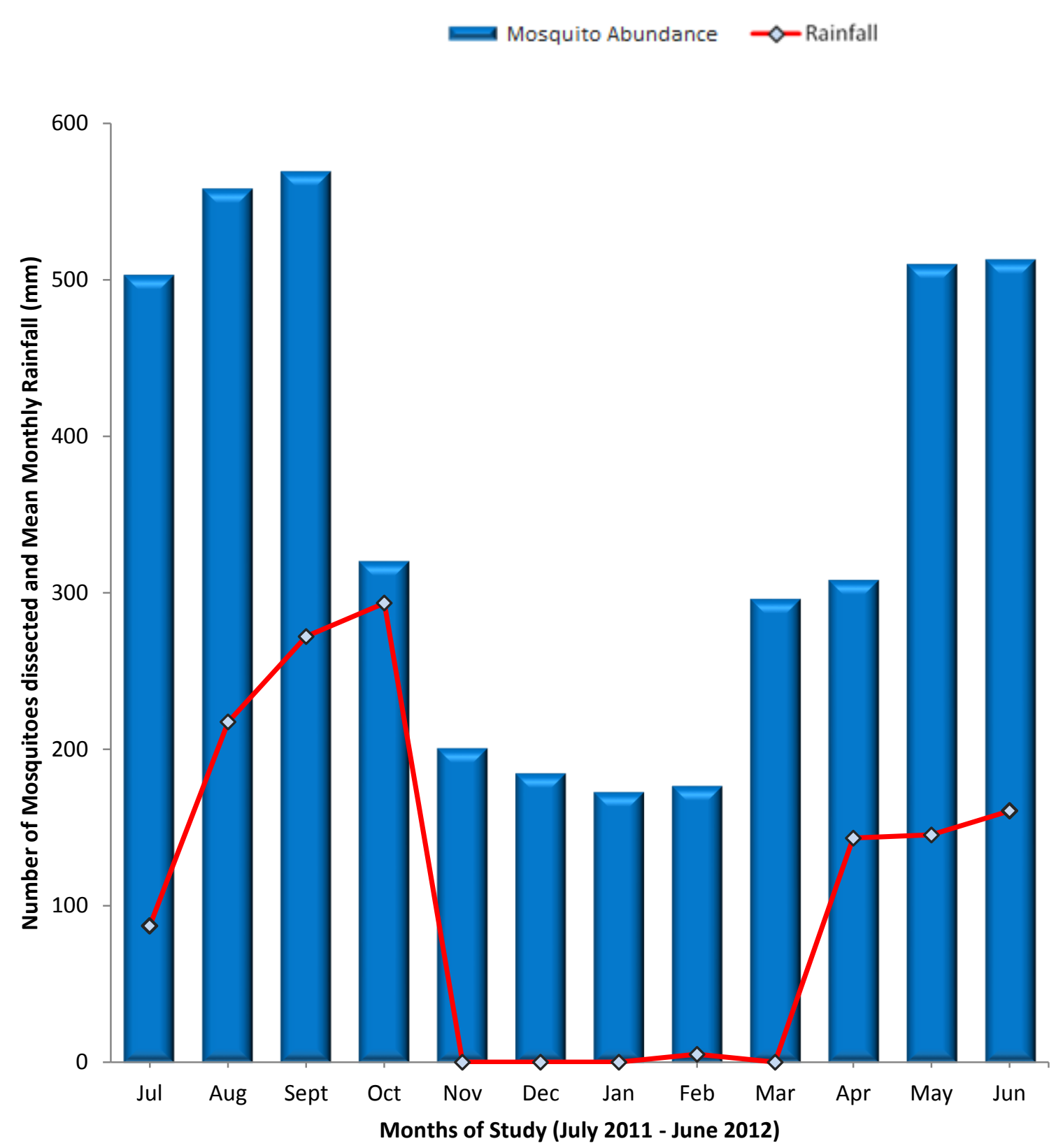

Fig. 3 Distribution of Mosquitoes in Relation to the Mean Monthly Register of Rainfall in Makurdi, Nigeria. 
Relationship between Weather Parameters and Female Mosquitoes' Abundance and Distribution in Makurdi, a Mosquito Infested Area in North Central Nigeria

Mosquito Abundance $\quad \prec$ Relative Humidity

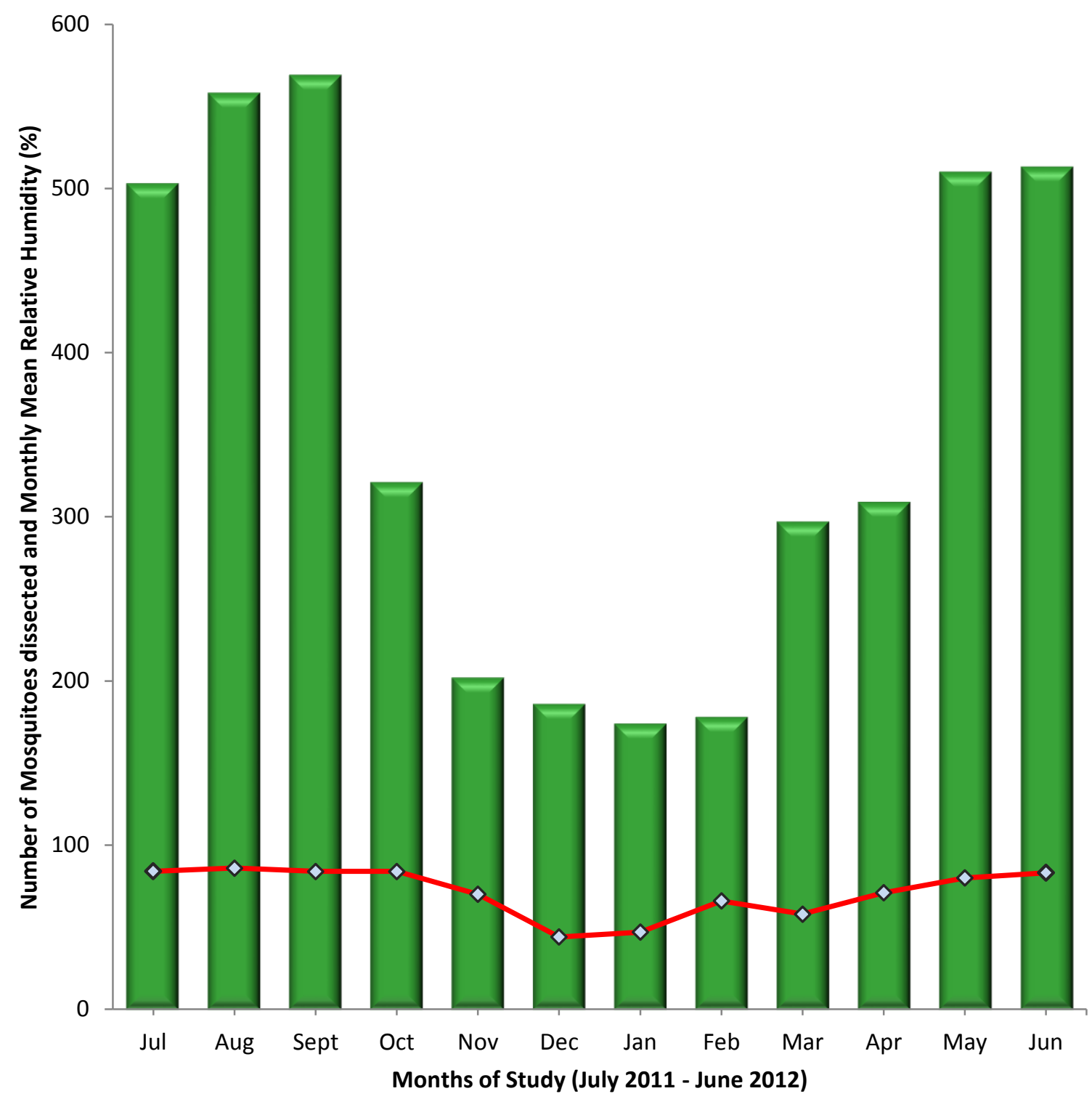

Fig.4. Distribution of Mosquitoes in Relation to the Mean Monthly Relative Humidity in Makurdi, Nigeria. 
Relationship between Weather Parameters and Female Mosquitoes' Abundance and Distribution in Makurdi, a Mosquito Infested Area in North Central Nigeria

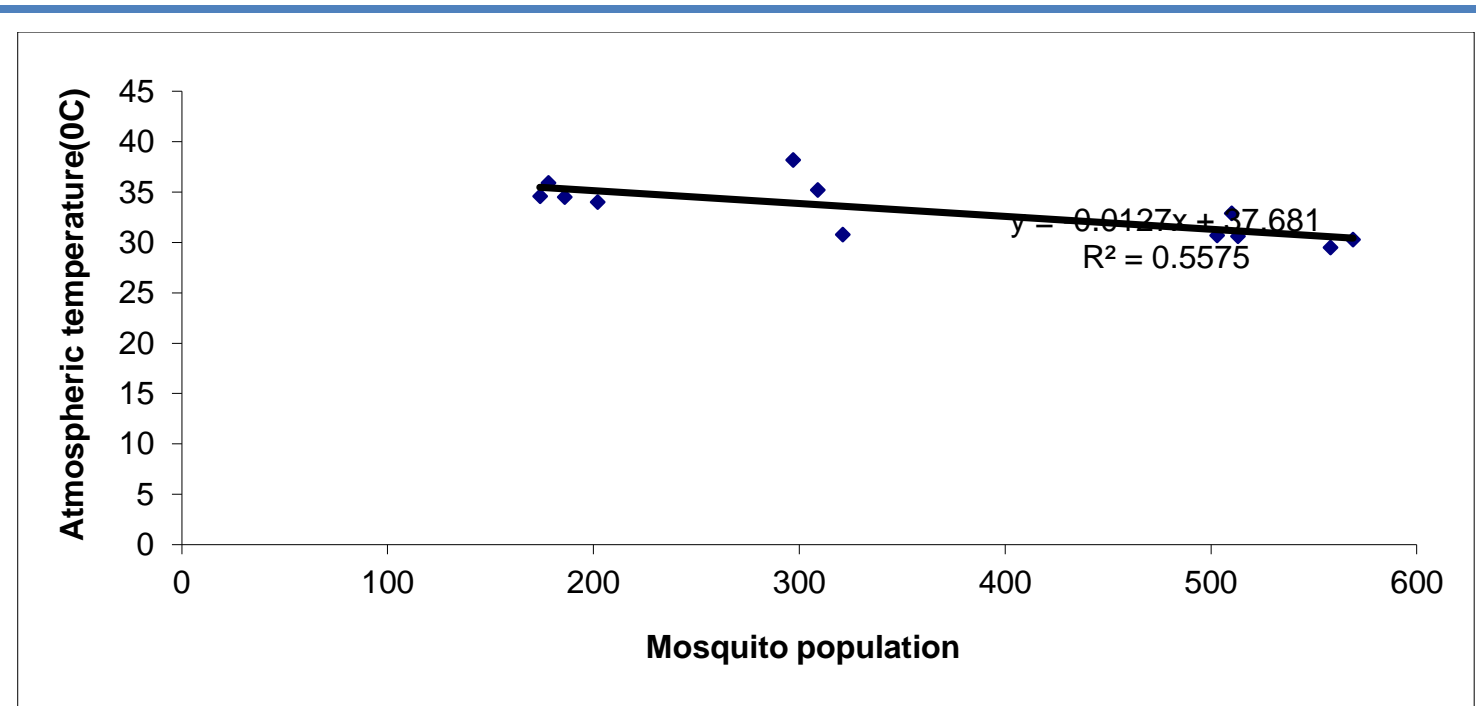

Figure 5. Regression curve showing the relationship between mean atmospheric Temperature and Mosquito Population in Makurdi

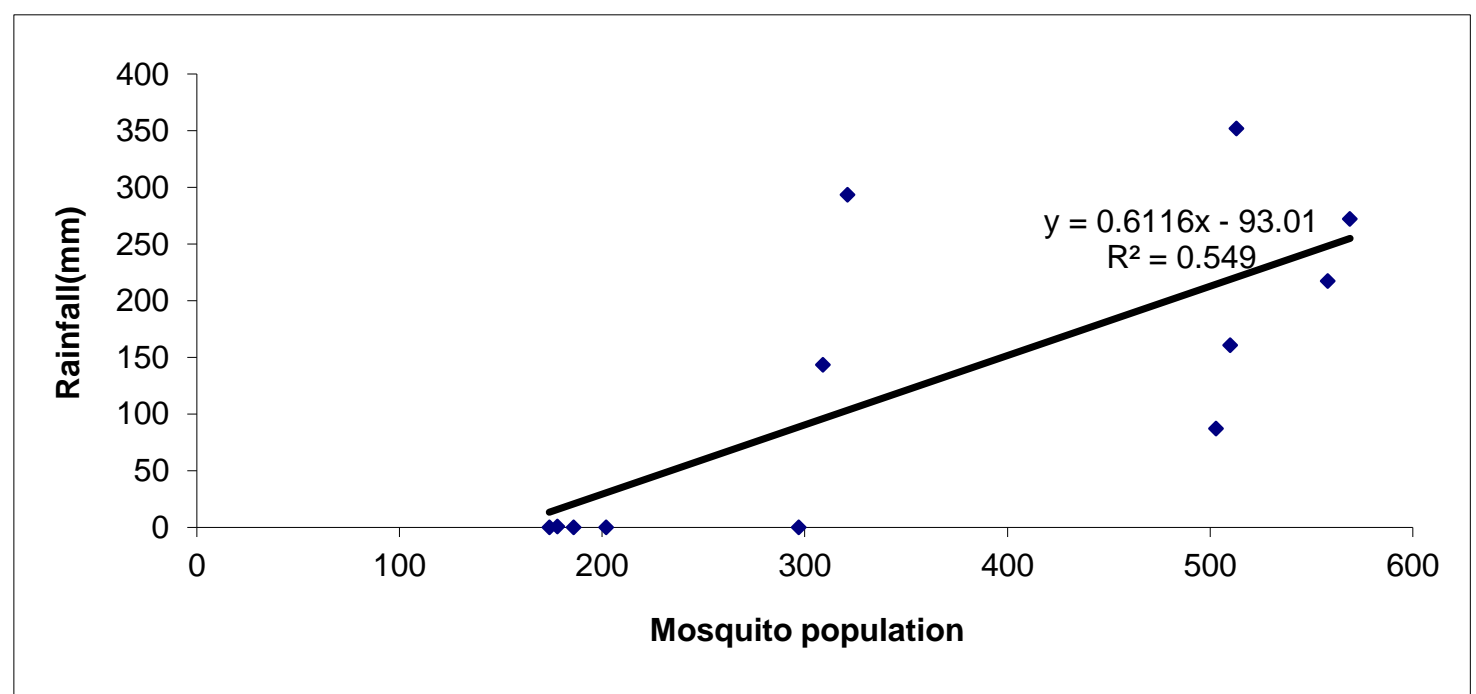

Figure 6. Regression curve showing the relationship between mean Rainfal and Mosquito Population in Makurdi

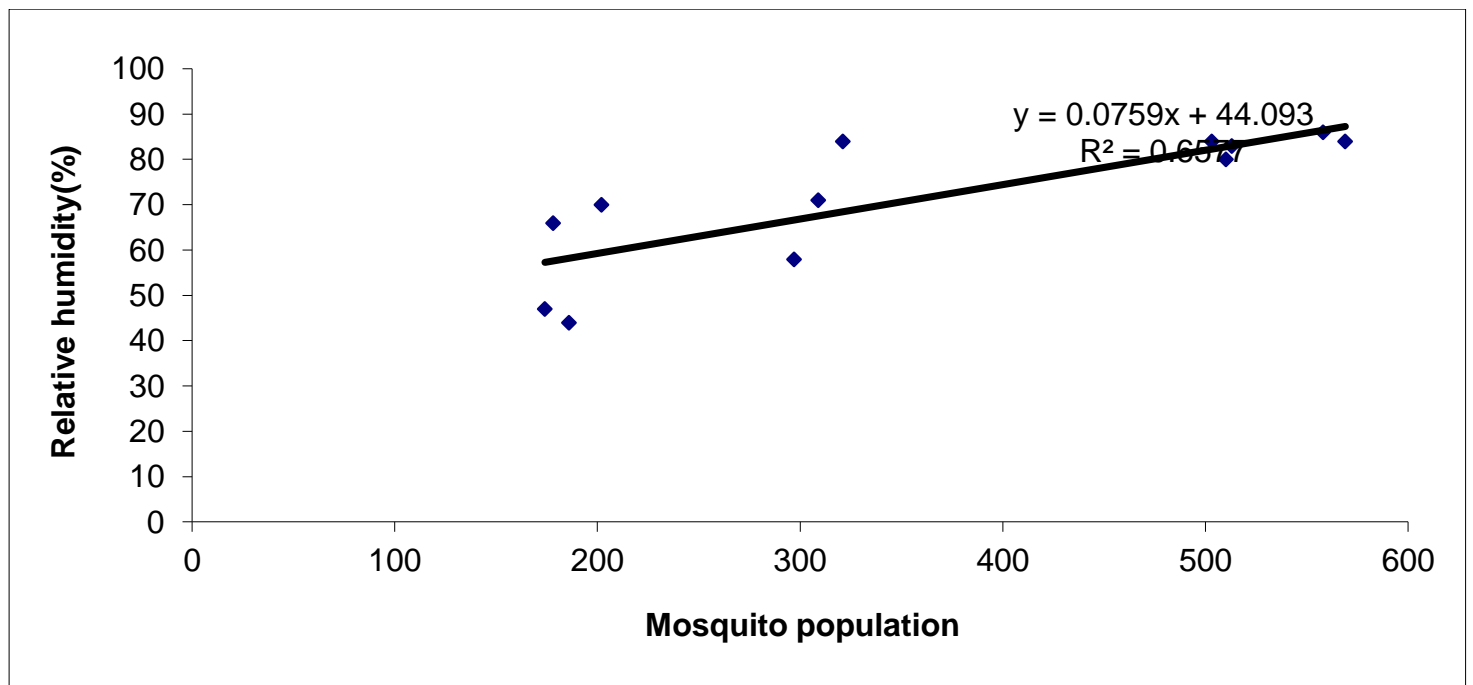

Figure 7. Regression curve showing the relationship between mean Relative Humidity and Mosquito Population in Makurdi 


\section{DISCUSSION}

Mean atmospheric temperature values obtained in Makurdi during this study were suitable for the mosquitoes' breeding, growth and survival. This result is in agreement with the reports of Laumann (2010), Githeko et al. (2000) and Service (2012). The temperature values were consistently high throughout the study period with peaks in February and March, 2012, just before the steady rains in April, 2012. The highest and lowest monthly mean temperature values during the study period imply that temperature had no adverse effect on the mosquito population in the study area for both dry and wet seasons. This is because the mean temperature values were within the optimum temperature range for insects, particularly mosquitoes as reported by Githeko et al. (2000). Optimum temperature of $32{ }^{0} \mathrm{C}$ helps in the development and hatching of mosquitoes' eggs and this signify increased transmission of the malaria and lymphatic filarial parasites. In line with the findings of Service (2012), the high temperature recorded in the present study would mean faster reproductive process in the mosquito vector populations in Makurdi.

Laumann (2010) and Ayanda (2009) reported that the incidence of malaria is influenced by weather factors which affect the ability of the main carrier of malaria parasites, anopheline mosquitoes, to survive or otherwise. This is corroborated by the results of the present study. Results obtained in the present survey showed a proportional relationship between the mosquito abundance, their distribution and, the weather parameters.

Results of the study have also revealed that rainfall had a marked effect on the mosquito vector populations in the study area. More mosquitoes were obtained in the wet season than the dry season. This agrees with Shililu et al. (1998) and Kasili et al. (2009), who separately but similarly reported that both mosquito populations and their Entomological Inoculation Rates (EIR) were reduced by decreasing rainfall amounts; and that both Culex quinquefasciatus and Anopheles species were found to dominate in the wet season.

The relative humidity values ranged from $44 \%$ to $86 \%$ with lowest values recorded from December, 2011 to March, 2012 (dry season) and higher values were recorded from July to October, 2011 (wet season) and then April to June, 2012 (second wet season) respectively. The records showed that relative humidity and rainfall had a similar pattern of effects on the mosquito populations in the study area.

This is also similar with the reports of Githeko et al. (2000) and Service (2012). The optimum temperature vis-avis the large mosquito population recorded in the present investigation corroborates the report of
Okogun et al. (2003) who reported that extreme relative humidity retards the activity of mosquitoes, thereby making them stationary in their breeding, biting and resting places, and that high relative humidity and cool shade are environmental factors preferred by mosquitoes for breeding.

Comparatively, the seasonality trend observed in terms of the relative abundance of mosquitoes for all the localities in this study is similar to the reports of two other studies in Southern Nigeria (Uttah and Uttah, 2009, Uttah et al., 2013a). This result also agrees with the reports of Gajanana et al. (1997) in India and Mwangangi et al. (2009) in the eastern part of Kenya. The recorded seasonality and relative abundance were expected in the present study because mosquito population density variations were closely linked to rainfall and temperature.

Weather data in this study therefore, suggest an increase in total seasonal rainfall for 2011 and 2012 seasons during which the present study was conducted, compared to the preceding years (Nigerian Metrological Agency (NMA), Tactical Air Command Makurdi personal communication). However, there was no apparent change in temperature patterns.

These and meteorological data on relative humidity were sufficient and convincing enough to make inference on mosquito distribution in the study area, contrary to the findings of Masaninga et al. (2012) who reported that these factors played insignificant roles in the mosquito distribution in their study area in "an urban setting in Zambia".

If the report by the National Institute of Allergy and Infectious Diseases (NIAID, 2007) for tropical areas is something to go by, then it is evident that malaria and other mosquito vector disease cases are likely to increase during the wet season in the Makurdi area.

Since mosquitoes must live long enough for the parasites to complete their development within them, environmental factors that affect their survival can influence disease incidence (Service, 2012). Weather data in correlation to the mosquito distribution data obtained in the present study are therefore, in line with NIAID's report stated above; the mosquito population increased with increased rainfall. In a similar manner, temperature values throughout the period of this investigation did not show adverse effect on the mosquito vector population. This coincides with the WHO report of 2000 on malaria seasonality in the tropics which holds that temperature is normally in favour of mosquito vectors throughout the year in these areas. This WHO report also related mosquito vector disease transmission with the availability of breeding sites, which in turn depends on the annual rainfall patterns. 
In the present study, temperature had favourably enhanced the population of the vector species across the four localities throughout the study period. Meanwhile, annual rainfall and the corresponding relative humidity were observed to have proportional effects on the mosquito vector population in the area (i.e the higher the amount of rainfall and relative humidity, the more the number of mosquitoes). There was a strong relationship between mean monthly rainfall totals and the relative abundance of the three major mosquito species identified in the study area.

This is however, parallel to the findings of Shililu et al. (1998) in Western Kenya who reported no significant correlation between the monthly rainfall totals and relative densities of Anopheles gambiae s.l. and Anopheles funestus respectively.

\section{CONCLUSION}

Temperature had no adverse effect on the mosquito population and distribution in Makurdi during the study period. However, rainfall and relative humidity markedly affected the abundance and distribution of the mosquitoes. Wet seasons had more mosquitoes across the study localities than dry seasons in this study because there were more breeding sites during the wet seasons than the dry season. It is therefore, recommended that proper drainage channels should be constructed and the damaged ones rehabilitated. Proper environmental sanitation should be enforced in the Makurdi township so as to evacuate logged waters/sewage and refuse that provide suitable breeding sites for the mosquito vectors.

\section{ACKNOWLEDGEMENTS}

We are grateful to Prof. (emeritus) Vajime, Charles Gbilekaa of the Department of Biological Sciences, Benue State University, Makurdi, Prof. Imandeh, Godwin Nyiutaha of the Department of Biological Sciences and Dr. Agada, Onuche Patience of the Department of Mathematics, Statistics and Computer Science, both of Federal University of Agriculture, Makurdi for vetting the manuscript and carrying out statistical analyses on the data obtained respectively.

\section{REFERENCES}

1) Abeyasingha, R.R., Yapabanadara, A.M., Kusumawathie, P.H..D., Perera, D., Peiris, B.S.L., Hewavitharane, H.M.P. and Harishchandra, R.D.J. (2009). Guidelines for Entomological Surveillance of Malaria Vectors in Sri Lanka. Anti-Malaria Campaign. Pp 62-67.

2) Aigbodion, F. I. and Nnoka, H. C. (2008). A Comparative study of the activities of Anopheles gambiae, Culex quinquefasciatus and Aedes aegypti (Diptera: Culicidae) by Pyrethrum spray collection in Benin City, Nigeria. Bioscience Research Communications, 20(3): 147-151.

3) Ayanda, O. I. (2009) Relative Abundance of Adult Female Anopheline Mosquitoes in Ugah, Nasarawa Stat

4) Federal Republic of Nigeria Official Gazette. (2007). Legal Notice on Publication of the

5) Details of the Breakdown of the National and State Provisional Totals, 2006 Census, 94:
6) B175-B198.

7) Gajanana, A., Rajendran, R., and Samuel, P.P. (1997). Japanese encephalitis in South Arcot district, Tamil Nadu, India. A three year longitudinal study of vector abundance and infection frequency, Journal of Medical Entomology, 34(6): 651-659. http://dx.doi.org/10.1093/jmedent/34.6.651

8) Gillies, M.T. and Coetzee, M. (1987). A supplement to the Anophelinae of Africa, South of

9) the Sahara. Johannesburg: Sought African Institute of Medical Research. 143Pp.

10) Githeko, A.K., Lindsay, S.W., Confalonieri, U. E and Patz, J.A. (2000). Climate Change and Vector-Borne Diseases: A regional Analysis. Bulletin of the World Health Organization, 78(9): 1136-1147

11) Goodman, D.S., Orelus, J.N., Roberts, J.M., Lammie, P.I., Streit, T.G. (2003). PCR and mosquito dissection as tools to monitor filarial infection levels following mass treatment, Filaria Journal, 2: Pp11.

12) Kasili, S., Oyieke, F., Wamae, C and Mbogo, C. (2009). Seasonal Changes of Infectivity Rates of Bancroftian Filariasis Vectors in Coast Province, Kenya. Journal of Vector Borne Diseases, 46: 219-224.

13) Laumann, V. (2010). Environmental Strategies to replace DDT and control Malaria. $2^{\text {nd }}$ extended edition: Pestizid Aktions-Netzwerk (PAN) e.V. 40Pp.

14) Masaninga, F., Daniel, C., Nkhuwa, W., Fastone, M., Goma C.S., Chanda, E., Kamuliwo, M., Kawesha, E.C., Siziya, S. and Babaniyi, O. (2012). Mosquito biting and malaria situation in an urban setting in Zambia. Journal of Public Health and Epidemiology, 4(9): 261 - 269.

15) Mwngangi, J.M., Muturi, E.J. and Mbogo, C.M. (2009) Seasonal Mosquito larval Abundance and Composition in Kibwezi, lower eastern Kenya, Journal of Vector Borne Diseases, 46(10): 65-71.

16) NEEF. (2008). National Environmental Education Foundation: Weather, Climate and Mosquitoes. Earth Gauge, www.earthgauge.net $2 \mathrm{Pp}$.

17) NIAID. (2007). National Institute of Allergy and Infectious Diseases.Understanding http://dx.doi.org/10.1002/9780471462422.eoct463

18) U.S. Department of Health and Human Services. National Institute of Heath Pulication,

19) No. 07-7139. www.niaid.nih.gov $32 \mathrm{Pp}$

20) NMA. (2011). Nigerian Meteorological Agency, Tactical Air Command Head Quarters Makurdi.

21) Nyagba, J. L. (1995). The geography of Benue State. In: A Benue Compendium. Denga, D. I. (ed) Calabar, Rapid Educational Publishers Ltd. Pp 85 - 97.

22) Oguoma, V.M., Nwaorgu, O.C., Mbanefo, E.C., Ikpeze, O.O., Umeh, J.M., Eneanya, C.I.

23) Species Composition of Anopheles mosquitoes in three villages of Uratta Owerri north Local Government Area of Imo State, Nigeria. Reviews in Infection, 1(4): 192-196.

24) Okogun, G. R.A., Nwoke, B.E.B., Okere, A. N., Anosike, J. C. and Esekhegbe, A. C. (2003). Epidemiological Implications of preferences of Breeding sites of mosquito species in Mid-Western Nigeria. Annals of Agricultural and Environmental Medicine, 10: 217 - 222.

25) Omudu, E. A. and Ochoga, J. O. (2011). Clinical epidemiology of lymphatic filariasis and community practices and perceptions amongst the Ado people of Benue State, Nigeria. African Journal of Infectious Diseases, 5(2):4-53. http://dx.doi.org/10.4314/ajid.v5i2.66514

26) Shililu, J. I., Maier, W. A. Seitz, H. M. and Orago, A. S. (1998). Seasonal density, sporozoite rates and entomological inoculation rates of Anopheles gambiae and Anopheles funestus in a high-altitude sugarcane growing zone in Western Kenya. Tropical Medicine and International Health 3(9): 706 - 710. http://dx.doi.org/10.1046/j.13653156.1998.00282.x

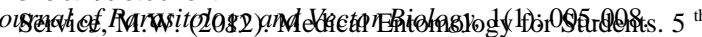
edn, Cambridge University Press, New York. 303Pp.

28) Udo, K. R. (1981). Geographical Regions of Nigeria. London, Morrison and Gibb Ltd. Pp 133 - 149. 
Relationship between Weather Parameters and Female Mosquitoes' Abundance and Distribution in Makurdi, a Mosquito Infested Area in North Central Nigeria

29) Ungureanu, E.M. (1972). Methods for Dissecting Dry Insects and Insects Preserved in Fixative Solutions or by Refrigeration. Bulletin of the World Health Organization 47: 239-244.

30) Uttah, E.C. and Uttah, C. (2009). Human settlement and behavioual triggers of sustained endemic filariasis in Eastern Nigeria. Paper presented at the 2009 Annual Conference of Parasitology and Public Health Society of Nigeria hosted at Usman Danfodio University Sokoto, Nigeria.
31) Uttah, E. C., Ibe, D. and Woken, G. N. (2013a). Filariasis control in Coastal Nigeria: Predictive. http://dx.doi.org/10.1155/2013/659468

32) World Health Organization, (1975). Manual on Practical entomology in Malaria. Part I and II.

33) Methods and Techniques. World Health Organization Offset Publication 13, Geneva, Switzerland. Pp 160.

34) World Health Organisation (2000). World Health Organization Expert Committee on Malaria. Technical Report Series. $\quad 892 \quad$ Geneva. http://dx.doi.org/10.1017/s0031182000058145 